\title{
Herbal remedies for depression and anxiety
}

\section{Edzard Ernst}

\begin{abstract}
Herbal remedies are used by many people suffering from anxiety or depression. It is therefore important to know whether they generate more good than harm. A systematic review of the published literature revealed trial data for Ginkgo biloba, Lavandula angustifolia, Hypericum perforatum, Valeriana officinalis, Crataegus oxyacantha, Eschscholzia californica, Matricaria recutita, Melissa officinalis, Passiflora incarnate and Piper methysticum. Only two of these herbal remedies are supported by sound evidence: Hypericum perforatum (St John's wort) for mild to moderate depression and Piper methysticum (kava) for anxiety. Neither is free of risks. Our knowledge of herbal remedies is incomplete and the subject merits rigorous study.
\end{abstract}

Complementary therapies have become hugely popular. A colleague and I estimated that, in 1999, the total expenditure for such treatments in the UK was $£ 1.6$ billion (Ernst \& White, 2000). There is reason to believe that the usage of complementary medicine in the UK has increased since then (Emslie et al, 2002). The lion's share of this amount is not covered by the NHS - by and large patients pay privately for complementary medicine. Herbal medicine is among the most popular complementary therapy: in the UK $34 \%$ of all users of complementary medicine take such remedies (Ernst \& White, 2000). Depression and anxiety are prominent indications for herbal medicines (Eisenberg et al, 1998; Kales et al, 2004; Roy-Byrne et al, 2005) and the majority of people with depression try complementary medicines (Silvers et al, 2006).

People's reasons for trying herbal medicines are complex (Ernst et al, 2001). British consumers have been shown to expect symptom relief, information, a holistic approach, improved quality of life and self-help advice from consulting complementary therapists (Richardson, 2004). American survey data suggest that significant associations exist between the specific domain of personality, coping strategies and social support on the one hand and use of complementary therapies on the other. Openness and perceived friend support were positively, and extroversion was inversely, correlated with the use of complementary medicine (Honda \& Jacobson, 2005). We should also not underestimate the lure of the popular media. About 41 million websites offer information on the subject, much of which is unreliable or outright dangerous (Ernst \& Schmidt, 2004). The UK daily press tends to be less than critical about complementary medicine (Ernst \& Weihmayr, 2000), and books for the layperson are frequently misleading: when colleagues and I extracted the recommendations from seven such texts, we found that the authors had recommended a total of 131 different treatments for anxiety and 87 for depression (Ernst et al, 2001).

In this article, I will review the evidence for or against herbal remedies as treatments for depression and anxiety. My assessment is based on a systematic review of the published literature (literature searches in Medline, EMBASE, the Allied and Alternative Medicine Database (AMED) and the Cochrane Library up to June 2005) with an emphasis on controlled clinical trials and systematic reviews (Ernst et al, 2006). Its focus is on herbal medicine; thus, non-herbal supplements are excluded even if the evidence is encouraging, as it is for omega- 3 fatty acids (Freeman et al, 2006).

Edzard Ernst qualified as a physician in Germany, where he was Professor of Physical Medicine and Rehabilitation (PMR) at Hannover Medical School. After a period as Head of the PMR Department at the University of Vienna (Austria) he came to the University of Exeter in 1993 to establish the first Chair in Complementary Medicine. He is Editor-in-Chief of the journal Focus on Alternative and Complementary Therapies (FACT) and founding editor of Perfusion. His work has been awarded 12 scientific prizes/awards and two Visiting Professorships. Professor Ernst served on the Medicines Commission of the British Medicines and Healthcare products Regulatory Agency (1994-2005) and on the Scientific Committee on Herbal Medicinal Products of the Irish Medicines Board. He is currently Director of Complementary Medicine at Peninsula Medical School (Universities of Exeter and Plymouth, 25 Victoria Park Road, Exeter EX2 4NT, UK. Email: Edzard. Ernst@pms.ac.uk). 


\section{Depression}

\section{Ineffective remedies}

Ginkgo biloba (maidenhair tree) was tested in a small $(n=27)$ trial involving people with 'winter depression'. The results did not suggest that this approach was superior to placebo (Lingaerde et al, 1999). It has, however, been shown to be effective for conditions such as dementia (Ernst et al, 2001).

\section{Promising remedies}

Lavandula angustifolia (common lavender) was compared with imipramine in a small randomised controlled trial (RCT) including 45 individuals with moderate depression (Akhondzadeh et al, 2004). Both treatments seemed similarly effective but the study had significant methodological shortfalls (e.g. it was not designed as an equivalence trial). Another trial designed along the same lines suggested that Crocus sativus (saffron crocus) and imipramine were similarly effective (Akhondzadeh et al, 2003). Unfortunately, the same limitations applied.

\section{Effective remedies}

The only herbal remedy that has been shown beyond reasonable doubt to be effective as a treatment for mild to moderate depression is Hypericum perforatum (St John's wort). The active ingredients of this herbal medicine are probably hypericin and/or hyperforin. Its antidepressive activity seems to be due to inhibition of both serotonin reuptake and monoamine oxidase.

An authoritative systematic review and metaanalysis included 30 RCTs involving individuals mostly (but not exclusively) with mild to moderate depression (Roder et al, 2004). The methodological quality of these trials was variable but many scored highest marks. Twenty five of them, involving a total of 2129 patients, compared St John's wort with placebo. The results strongly favoured the former over the latter (risk ratio $=0.66,95 \%$ CI $0.57-0.78$, number needed to treat $=42$ ). Five trials, involving a total of 2231 patients, compared St John's wort with conventional antidepressants (including selective serotonin reuptake inhibitors (SSRIs)). The risk ratio of 0.96 indicates equivalence of these approaches. A subsequent Cochrane Review (Linde et al, 2005) reported similarly encouraging results.

So why use this herbal remedy if it is not better than conventional drugs? One answer could be that many patients prefer 'natural' treatments. A perhaps more convincing answer is that its adverse effects profile is preferable. In fact, St John's wort is associated with similar frequency and severity of adverse effects as placebo. There are, however, two caveats. Extracts of St John's wort powerfully interact with the cytochrome P450 enzyme system and thus increase the plasma level of a wide range of other drugs (Mills et al, 2005). It seems to follow that it is safe only for people who use no other medication. The second caveat is the suspicion that St John's wort can trigger psychoses, particularly in patients who concomitantly take SSRIs (Izzo \& Ernst, 2001).

\section{Anxiety \\ Ineffective remedies}

No anxiolytic effects of valerian (Valeriana officinalis) extract were noted in an RCT involving 66 people with generalised anxiety disorder (Adreatini $e t$ al, 2002).

\section{Promising remedies}

A large RCT found that a combination of Crataegus oxyacantha (hawthorn), Eschscholzia californica (Californian poppy) and magnesium was more effective than placebo in reducing anxiety in 264 individuals with generalised anxiety disorder (Hanus et al, 2004). There is some evidence for the efficacy of Matricaria recutita (German chamomile) in the treatment of anxiety (Wong et al, 1998), but the study was methodologically weak. Short-term anxiolytic effects were noted after administration of Melissa officinalis (lemon balm) to healthy volunteers (Kennedy et al, 2004). Passiflora incarnata (passion flower) generated encouraging anxiolysis in an RCT with 36 people who had generalised anxiety disorder (Akhondzadeh et $a l, 2001)$. Even though these results are encouraging they do require independent replication before firm recommendations can be made.

\section{Effective remedies}

The only herbal remedy that is demonstrably effective in reducing anxiety is Piper methysticum (kava). Our Cochrane Review included 11 RCTs, involving a total of 645 patients (Pittler \& Ernst, 2003). The methodological quality of these studies was variable but some were excellent. Without exception, these trials showed anxiolytic effects of kava that were superior to placebo.

Despite these clearly positive efficacy data, kava cannot currently be recommended for clinical use. This is because it has been associated with (sometimes severe) hepatotoxicity (Ernst, 2004). Recently there has been much debate about whether this association is causal or not. At present, however, this herbal remedy remains banned from the UK market. 
Table 1 Herbal medicines for depression and anxiety

\begin{tabular}{|c|c|c|c|}
\hline & Not effective & Promising & Effective \\
\hline Depression & Ginkgo biloba (maidenhair tree) & $\begin{array}{l}\text { Lavandula angustifolia (common } \\
\text { lavender) } \\
\text { Crocus sativus (saffron crocus) }\end{array}$ & $\begin{array}{l}\text { Hypericum perforatum (St John's } \\
\text { wort) }\end{array}$ \\
\hline Anxiety & Valeriana officinalis (valerian) & $\begin{array}{l}\text { Matricaria recutita (German } \\
\text { chamomile) } \\
\text { Melissa officinalis (lemon balm) }\end{array}$ & $\begin{array}{l}\text { Piper methysticum (kava) (but } \\
\text { banned in UK) }\end{array}$ \\
\hline
\end{tabular}

\section{Comments}

Most clinicians will find this summary of the trial data (Table 1) less than encouraging: apart from St John's wort, there is hardly anything within the realm of herbal medicine that can be recommended to patients suffering from anxiety or depression. Some remedies might work but, at present, we cannot be sure. Why is there still so much uncertainty in herbal medicineafter all, it is millennia older than pharmacology?

\section{Research difficulties}

Herbal medicines are mixtures of many active ingredients. They differ from synthetic drugs in several ways (Table 2). Often it is more than one herbal active ingredient that brings about the clinical effects we observe in patients. In many instances we have not yet identified any or all of the active ingredients. Moreover, the quality of herbal remedies varies considerably (Garrard et al, 2003) owing to a range of factors: plant species, soil, climate, storage, extraction method, etc. This complexity complicates research.

The clinical effects of herbal medicines are usually moderate and often appear only after prolonged periods of administration. Clinical trials therefore need to be large and long-term. These facts tend to render clinical trials more expensive. Even though the sector as a whole achieves a sizeable turnover (Wright, 2005), single herbal manufacturers are usually relatively small and, compared with 'big pharma', they are typically not financially powerful. To make things worse, normally there is no patent protection of herbal extracts. Thus, there is little money to support expensive trials and even less impetus to spend it on research. This already bleak situation will be further aggravated by recent legislation: the European Directive on Traditional Herbal Medicinal Products, which came into force in October 2005, does not require proof of efficacy through clinical trials for registering herbal medicines under this scheme. Thus the incentive to conduct such research approaches zero.

Is there a way out of this dilemma? One solution would be to follow the American example and set aside 'ring-fenced' public funds for supporting research into herbal medicine. Research that emerges from initiatives funded by the National Institutes of Health is usually of outstanding methodological quality. Perhaps the UK authorities should consider this approach and develop a strategy along similar lines.

\section{Product safety}

From a clinical perspective, we need to consider not just efficacy but also (and perhaps foremost) safety

Table 2 Herbal medicines $v$. synthetic drugs

Herbal
Active ingredients often not known
Pure compound not available
Raw material limited
Quality variable
Mechanism often unknown
Toxicology often unknown
Long tradition of use
Wide therapeutic window
Adverse effects rare

Herbal

\section{Synthetic}

Active ingredient known

Pure compound available

Raw material unlimited

Quality constant

Mechanism known

Toxicology known

Short tradition of use

Narrow therapeutic window

Adverse effects frequent 


\section{Box 1 Major safety issues with herbal} medicine

- Inherent toxicity (e.g. liver damage after kava intake)

- Contamination (e.g. heavy metals in Ayurvedic preparations)

- Adulterations (e.g. sildenafil in herbal aphrodisiacs)

- Interactions (e.g. St John's wort lowers the plasma level of about half of prescription drugs)

\section{Box 2 Examples of interactions between herbal and synthetic medicines}

- St John's wort can increase the effects of conventional SSRIs

- Kava can interact with levodopa and alprazolam, causing extrapyramidal symptoms or lethargy

- Valerian can interact with loperamide and fluoxetine, causing delirium

- Evening primrose oil can interact with phenothiazide, causing epileptic seizures

Data from Johne \& Roots (2005)

(Box 1). Consumers often assume herbal medicines to be safe; a survey conducted in Israel, for instance, showed that $56 \%$ of them believed they cause no sideeffects at all (Giveon et al, 2004). Unfortunately, this is not true. Most herbal remedies have been associated with (usually mild and transient) adverse effects (Ernst, 2000). In addition, a systematic review showed that herbal medicines taken for non-psychiatric indications can cause psychiatric adverse effects, including delirium, coma, confusion, hallucinations, mood disturbances and seizures (Ernst, 2003). Research also confirms that many herbal medicines have the potential to interact with prescribed drugs (Box 2). The notion that 'natural' equals 'safe' can therefore be dangerously misleading.

In conclusion, the scientific knowledge about the potential benefits or harms of herbal treatments for anxiety or depression is incomplete and the information patients receive can be highly misleading. Psychiatrists should be aware of the essential facts and advise their patients accordingly.

\section{Declaration of interest}

None.

\section{References}

Adreatini, R., Sartori, V. A., Seabra, M. L., et al (2002) Effect of valpotriates (valerian extract) in generalised anxiety disorder: a randomised placebo-controlled pilot study. Phytotherapy Research, 16, 650-654.

Akhondzadeh, S., Naghavi, H. R., Vazirian, M., et al (2001) Passionflower in the treatment of generalised anxiety: a pilot double-blind randomized controlled trial with oxazepam. Journal of Clinical Pharmacy and Therapeutics, 26, 363-367.

Akhondzadeh, S., Kashani, L., Fotouhi, A., et al (2003) Comparison of Lavandula angustifolia Mill. tincture and imipramine in the treatment of mild to moderate depression: a double-blind, randomized trial. Progress in Neuro-Psychopharmacology and Biological Psychiatry, 27, 123-127.

Akhondzadeh, S., Fallah-Pour, H., Afkham, K., et al (2004) Comparison of Crocus sativus L. and imipramine in the treatment of mild to moderate depression: a pilot double-blind randomized trial. BMC Complementary and Alternative Medicine, 4, 12.

Eisenberg, D., David, R. B., Ettner, S. L., et al (1998) Trends in alternative medicine use in the United States: 1990-1997. JAMA, 280, 1569-1575.

Emslie, M. J., Campbell, M. K. \& Walker, K. A. (2002) Changes in public awareness of, attitudes to, and use of complementary therapy in North East Scotland: surveys in 1993 and 1999. Complementary Therapies in Medicine, 10, 148-153.

Ernst, E. (2000) Risks associated with complementary therapies. In Meyler's Side Effects of Drugs (eds M. N. G. Dukes \& I. K. Aronson) (14th edn), pp. 1649-1681. Elsevier.

Ernst, E. (2003) Serious psychiatric and neurological adverse effects of herbal medicines - a systematic review. Acta Psychiatrica Scandinavica, 108, 83-91.

Ernst, E. (2004) Second thoughts about kava. American Journal of Medicine, 113, 347-348.

Ernst, E. \& Schmidt, K. (2004) 'Alternative' cures for depression - how safe are web sites? Psychiatry Research, 129, 297-301.

Ernst, E. \& Weihmayr, T. (2000) UK and German media differ over complementary medicine. BMJ, 321, 707.

Ernst, E. \& White, A. R. (2000) The BBC survey of complementary medicine use in the UK. Complementary Therapies in Medicine, 8, 32-36.

Ernst, E., Pittler M. H., Stevinson, C., et al (2001) The Desktop Guide to Complementary and Alternative Medicine. Mosby.

Ernst, E., Boddy, K., Pittler, M. H., et al (2006) The Desktop Guide to Complementary and Alternative Medicine: An Evidence-Based Approach (2nd edn). Mosby.

Freeman, M. P., Hibbeln, J. R., Wisner, K. L., et al (2006) Omega-3 fatty acids: evidence basis for treatment and future research in psychiatry. Journal of Clinical Psychiatry, 67, 1954-1967.

Garrard, J., Harms, S., Eberly, L. E., et al (2003) Variations in product choices of frequently purchased herbs. Archives of Internal Medicine, 163, 2290-2295.

Giveon, S. M., Liberman, N., Klang, S., et al (2004) Are people who use natural drugs aware of their potentially harmful side effects and reporting to family physician? Patient Education and Counseling, 53, 5-11.

Hanus, M., Lafon, J., \& Mathieu, M. (2004) Double-blind, randomised, placebo-controlled study to evaluate the efficacy and safety of fixed combination containing two plant extracts (Crataegus oxyacantha and Eschscholtzia californica) and magnesium in mild-to-moderate anxiety disorders. Current Medical Research and Opinion, 20, 63-71.

Honda, K. \& Jacobson, J. S. (2005) Use of complementary and alternative medicine among United States adults: the influences of personality, coping strategies, and social support. Preventive Medicine, 40, 56-53.

Izzo, A. A. \& Ernst, E. (2001) Interactions between herbal medicines and prescribed drugs: a systematic review. Drugs, 15, 2163-2175.

Johne, A. \& Roots, I. (2005) Clinical drug interactions with medicinal herbs. Evidence-Based Integrative Medicine, 2, 207228.

Kales, H. C., Blow, F. C., Welsh, D. E., et al (2004) Herbal products and other supplements: use by elderly veterans with depression and dementia and their caregivers. Journal of Geriatric Psychiatry and Neurology, 17, 25-31. 
Kennedy, D. O., Little, W. \& Scholey, A. B. (2004) Attenuation of laboratory-induced stress in humans after acute administration of Melissa officinalis (lemon balm). Psychosomatic Medicine, 66, 607-613.

Linde, K., Mulrow, C., Berner, M., et al (2005) St John's wort for depression. Cochrane Database of Systematic Reviews, issue 2. Art. no. CD000448. Wiley InterScience.

Lingaerde, O., Foreland, A. R. \& Magnusson, A. (1999) Can winter depression be prevented by Ginkgo biloba extract? A placebo-controlled trial. Acta Psychiatrica Scandinavica, 100, 62-66.

Mills, E., Montori, V. M., Wu, P., et al (2005) Interaction of St John's wort with conventional drugs: systematic review of clinical trials. BMI, 329, 27-30.

Pittler, M. H. \& Ernst, E. (2003) Kava extract for treating anxiety. Cochrane Database of Systematic Reviews, issue 1. Art. no. CD003383. Wiley InterScience.

Richardson, J. (2004) What patients expect from complementary therapy: a qualitative study. American Journal of Public Health, 94, 1049-1053.

Roder, C., Schaefer, M. \& Leucht, S. (2004) Meta-analysis of effectiveness and tolerability of treatment of mild to moderate depression with St. John's Wort [in German]. Fortschritte der Neurologie-Psychiatrie, 72, 330-343.

Roy-Byrne, P. P., Bystritsky, A., Russo, J., et al (2005) Use of herbal medicine in primary care patients with mood and anxiety disorders. Psychosomatics, 46, 117-122.

Silvers, K. M., Woolley, C. C. \& Hedderley, D. (2006) Dietary supplement use in people being treated for depression. Asia Pacific Journal of Clinical Nutrition, 15, 30-34.

Wong, A. H. C., Smith, M. \& Boon, H. S. (1998) Herbal remedies in psychiatric practice. Archive of General Psychiatry, 55, 10331044.

Wright, T. (2005) Herbs and botanicals update. Nutraceuticals World (July/August), 50-62.

\section{MCQs}

1 In 1999 the total annual expenditure for complementary therapies in the UK was estimated to be:

a $£ 16$ billion

b $£ 1.6$ billion

c $£ 1.6$ million

d $£ 0.16$ million

e $£ 160$ billion.
2 The number of websites currently informing patients about 'alternative medicine' is about:

a 40 thousand

b 4 million

c 4 thousand

d 40 million

e 400 million.

3 Efficacy of St John's wort is best documented for:

a insomnia

b anxiety

c depression

d hay fever

e none of the above.

4 Kava, used for anxiety, is associated with:

a memory loss

b liver problems

c kidney problems

d gastrointestinal problems

e impaired vision.

5 The hypothesis that 'natural' equals 'safe':

a is biologically plausible

$\mathrm{b}$ is false and misleading

c is a well-established fact

$\mathrm{d}$ is the subject of current research

e was first advanced by Samuel Hahnemann.

\section{CORRIGENDUM}

Rowland, J. P, Rigby, J., Harper, A. C., et al (2007) Cardiovascular monitoring with acetylcholinesterase inhibitors: a clinical protocol. APT, 13, 178-184. doi: 10.1192/apt.bp.106.002725.

On p. 184 the stem to the fourth MCQ should read:

4 An AChE inhibitor should be continued if: 